\title{
Scientific Validation of Gentiana kurroo Royle for Anti-Inflammatory and Immunomodulatory Potential
}

\author{
Khan Mubashir, ${ }^{1}$ Khalid Ghazanfar, ${ }^{2}$ Bashir A. Ganai, ${ }^{1}$ Seema Akbar, \\ Akhtar H. Malik, ${ }^{3}$ and Akbar Masood ${ }^{1}$ \\ ${ }^{1}$ Department of Biochemistry, University of Kashmir, Srinagar 190 006, India \\ ${ }^{2}$ Regional Research Institute of Unani Medicine, Kashmir University Campus, Srinagar 190 006, India \\ ${ }^{3}$ Centre for Biodiversity and Taxonomy (CBT), Department of Botany, University of Kashmir, Srinagar 190 006, India
}

Correspondence should be addressed to Bashir A. Ganai; bbcganai@gmail.com

Received 24 November 2013; Accepted 18 January 2014; Published 23 February 2014

Academic Editors: A. Kamal and J. Meseguer

Copyright (C) 2014 Khan Mubashir et al. This is an open access article distributed under the Creative Commons Attribution License, which permits unrestricted use, distribution, and reproduction in any medium, provided the original work is properly cited.

\begin{abstract}
Gentiana kurroo Royle is a critically endangered medicinal plant species endemic to the northwestern Himalayas. This plant was studied for the immunomodulatory and anti-inflammatory potential. Carrageenan paw edema model was used to study the potential of the drug in inflammation in Wistar rats. SRBC specific haemagglutination titre and DTH assays were carried out in Balb/C mice for observing the effect of test drugs on immune system. The plant extracts were found to be active against inflammation. The methanolic fraction was observed to be the most effective in inhibition of paw edema with the inhibitory potential of $47.62 \%$. In immunomodulation studies the plant extracts showed the immunosuppressant activity. Methanolic fraction was observed to have maximum potential for the suppression of both humoral (57.57\% and 54.05\%) and cell mediated immunity $(65.27 \%$ and $75 \%)$. From these studies, it can be concluded that the extracts of plant are having anti-inflammatory and immunosuppressant activity. Since in chronic inflammation like arthritis there is the involvement of immune system, this plant may serve as an alternative for the treatment of autoimmune diseases like arthritis.
\end{abstract}

\section{Introduction}

A number of medicinal herbs have been found to be useful for pharmacological activities, like anti-inflammatory and immunosuppressive effects. Throughout the world different types of inflammatory diseases like rheumatic diseases are very common [1]. A major cause in development of inflammatory and autoimmune diseases is alteration in the T-cell responses and irregular functioning of the immune system [2]. Any changes in the immune response involving induction, expression, amplification, or inhibition of any part or phase of the immune response refer to immunomodulation. The agents that can modulate the immune response are traditionally called the immunomodulators and are stimulatory or suppressive in their effect [3].

The immune system can be modulated by a large number of immunosuppressive drugs that have different mechanisms of action. Most common of these drugs are the glucocorticoids used widely in inflammatory disease management.
These drugs by affecting gene transcription events cause inhibition of various immune functions $[4,5]$. An alternative to conventional chemotherapy is the use of herbal products for immune suppression and there is an increasing demand to discover new drugs with fewer side effects. The plant products which have been found to be able to affect the functioning of the immune system are mainly the primary and secondary metabolites [6]. Such compounds with the capacity to inhibit cellular and humoral immune responses can have useful applications in some immune-mediated disorders including autoimmune diseases [7]. Because of the side effects associated with the synthetic drugs and increased demand of herbal medicines for therapeutic applications, it has become necessary to exploit the medicinal potential of plant species.

Gentiana kurroo Royle belongs to the family Gentianaceae and is a critically endangered (CR) medicinal plant species, endemic to the northwestern Himalayas. The drug 
(rootstock) of this plant is administered in fevers and urinary complaints, also used as a bitter tonic, antiperiodic, expectorant, antibilious, astringent, stomachic, antihelminthic, blood purifier, and carminative [8]. The methanolic root extract of this plant contains tannins, alkaloids, saponins, cardiac glycosides, terpenes, flavonoids, phenolics, and carbohydrates. The root extract of this plant has been found to have an analgesic activity [9]. The ethanolic extract of the flower tops of this plant contains alkaloids, flavonoids, glycosides, free phenols, and sterols/terpenes and thus has been found to show an antiinflammatory activity [10].

The present study was carried out to evaluate the role of different fractions of G. kurroo in inflammation and immunomodulation.

\section{Materials and Methods}

2.1. Collection and Identification of Plant Material. The plant material was procured from subalpine region in Dachigam and identified in the Centre of Plant Taxonomy (COPT), Department of Botany, University of Kashmir. The specimen is retained in the herbarium of COPT vide voucher number 1804-KASH.

2.2. Preparation of Extracts. The whole plant was washed, cut into small pieces, and shade-dried. The plant material was pulverized into coarse powder and extracted successively using petroleum ether, ethyl acetate, methanol, and water, respectively, by soxhlet extraction. The solvents were allowed to evaporate in a rotary evaporator at $40^{\circ}-45^{\circ} \mathrm{C}$ and the extracts obtained were stored in a refrigerator at $4^{\circ} \mathrm{C}$. The yields of the petroleum ether, ethyl acetate, methanol, and aqueous extracts were $5.6,4.3,5.3$, and $4.2 \%(\mathrm{w} / \mathrm{w})$, respectively.

2.3. Animals. Male albino Wistar rats (120-140 gm) in groups of 4 each were used for anti-inflammatory study. Drugs were prepared in 1\% tween 20 and administered orally at doses of $250 \mathrm{mg} / \mathrm{kg}$ bw. Diclofenac was used as an anti-inflammatory drug at a dose of $20 \mathrm{mg} / \mathrm{kg}$ (p.o).

Male Balb/C mice, 8-10 weeks old and weighing 18-22 g, in groups of five each, were used for the immunomodulatory study. Drugs for oral administration were freshly prepared as a homogenised suspension of different extracts of G. kurroo at doses of $100 \mathrm{mg} / \mathrm{kg}$ each in $1 \%$ tween 20 and administered orally, once daily for the duration of the experiment to Balb/C mice. Cyclophosphamide was used as the standard immunosuppressive agent at $50 \mathrm{mg} / \mathrm{kg}$ (p.o).

The animals were housed under standard laboratory conditions with a temperature of $(25 \pm 2)^{\circ} \mathrm{C}$, relative humidity of $(55 \pm 10) \%$, and $12 / 12 \mathrm{~h}$ light-dark cycles and fed with standard pellet diet (Lipton India Ltd.) and water was given ad libitum. None of the animals was sacrificed throughout the study.

2.4. Chemicals. Tween 20, cyclophosphamide, and diclofenac were purchased from Sigma chemical Co. (St. Louis, MO). All other reagents used were of analytical grade.
Fresh blood was collected from healthy sheep in the animal house. Sheep red blood cells (SRBCs) were washed thrice with normal saline adjusted to a concentration of $1 \mathrm{~mL}$, containing $5 \times 10^{9}$ cells for immunisation and challenge.

2.5. Experimental Protocols. All experimental protocols and the number of animals used for the experimental work were duly approved by the Institutional Animals Ethics Committee (IAEC) of Indian Institute of Integrative Medicine (CSIR), Canal Road Jammu (CPCSEA registration no. 67/CPCSEA/99).

2.5.1. Carrageenan-Induced Paw Edema. Carrageenaninduced paw edema model [11] was utilized to assess the acute anti-inflammatory potential of the test samples. Animals were divided into six groups $(n=4)$. Group I served as control, rats in groups II-V were administered with plant extracts, and group VI was used as positive control. All drugs were given orally $45 \mathrm{~min}$ before Carrageenan injection. Carrageenan was prepared in normal saline $(1 \%)$ and $0.1 \mathrm{~mL}$ was injected into the subplantar region of left hind paw. The volume of both paws was measured with volume differential meter (520-R, IITC Life Science, USA) after 4 hrs with the volume of right paw taken as uninjected paw volume. Percent of inhibition was calculated by taking mean of the difference of right and left paw edema, using the formula

$$
\% \text { inhibition }=\frac{C-T}{C} \times 100 \text {, }
$$

where $C$ represents mean edema in the control group and $T$ represents mean edema in the treated group.

2.5.2. Humoral Antibody Response. The mice were divided into 6 groups, each consisting of 5 animals. Mice in group I (control) were given $1 \%$ tween $20,0.2 \mathrm{~mL} / \mathrm{mice}$ for 14 days. Mice in groups II-V were given a drug dose of $100 \mathrm{mg} / \mathrm{kg} \mathrm{bw}$ (orally) for 14 days. Mice in group VI were given cyclophosphamide $50 \mathrm{mg} / \mathrm{kg}$ on day 1 and continued for 14 days. The animals were immunised by injecting $200 \mu \mathrm{L}$ of $5 \times 10^{9}$ SRBCs/mL, intraperitoneally (i.p) on day 1 . Blood samples were collected in microliter tubes from individual animals of all the groups by retroorbital vein puncture on day 7 and day 14. The blood samples were centrifuged and the serum was separated. Then haemoglutination primary and secondary titres were performed $[12,13]$.

2.5.3. Delayed-Type Hypersensitivity. This method was carried out to determine the effect of extracts on the cellmediated immunity. Animals were divided into six groups of 5 each. Group I served as sensitized control, as in humoral antibody titre. Mice in groups II-V were administered extracts of G. kurroo after SRBC's sensitization and once daily for seven days. Cyclophosphamide $(50 \mathrm{mg} / \mathrm{kg})$ was administered as standard T-cell suppressor (group VI). The mice were challenged by injecting the same amount of SRBCs subcutaneously into the right hind footpad, whereas left hind footpad served as control $[14,15]$. The footpad thickness was 
TABLE 1: Effect of different extracts of Gentiana kurroo Royle at a dose of $250 \mathrm{mg} / \mathrm{kg}$ on Carrageenan-induced paw edema in rats (mean \pm S.E) $(n=4)$.

\begin{tabular}{lcccccc}
\hline Serial number & Groups & Dose $(\mathrm{mg} / \mathrm{kg})$ & Initial paw volume $(\mathrm{mL})$ & Paw volume after $4 \mathrm{~h}(\mathrm{~mL})$ & Edema $(4 \mathrm{~h})$ & \% age inhibition $(4 \mathrm{~h})$ \\
\hline 1 & Control & NS & $2.07 \pm 0.075$ & $1.02 \pm 0.048$ & $1.05 \pm 0.029^{\mathrm{a}}$ & - \\
2 & GMT & 250 & $1.55 \pm 0.029$ & $1 \pm 0.041$ & $0.55 \pm 0.029^{\mathrm{b}}$ & 47.62 \\
3 & GET & 250 & $1.8 \pm 0.071$ & $1 \pm 0.041$ & $0.8 \pm 0.071^{\mathrm{ac}}$ & 23.81 \\
4 & GPT & 250 & $1.95 \pm 0.056$ & $0.97 \pm 0.041$ & $0.97 \pm 0.074^{\mathrm{bc}}$ & 7.62 \\
5 & GAQ & 250 & $1.72 \pm 0.025$ & $0.97 \pm 0.025$ & $0.75 \pm 0.029^{\mathrm{b}}$ & 28.57 \\
6 & Diclo & 20 & $1.57 \pm 0.025$ & $1.1 \pm 0.041$ & $0.47 \pm 0.025^{\mathrm{c}}$ & 55.24 \\
\hline
\end{tabular}

Values along the same column with different superscripts are statistically significant to each other using Tukey's HSD test $(P<0.05)$. GMT: methanolic extract; GET: ethyl acetate extract; GPT: petroleum ether extract; GAQ: aqueous extract; Diclo: diclofenac.

TABLE 2: Effect of different extracts of Gentiana kurroo Royle on SRBC specific humoral immune response in Balb/C mice. (mean \pm S.E) $(n=5)$.

\begin{tabular}{lccc}
\hline & \multicolumn{2}{c}{ Humoral response } & \\
Groups & Dose $(\mathrm{mg} / \mathrm{kg})$ & Primary titre & Secondary titre \\
\hline Control & SRBC & $6.6 \pm 0.24^{\mathrm{bc}}$ & $7.4 \pm 0.24^{\mathrm{a}}$ \\
Methanolic fraction & 100 & $2.8 \pm 0.22^{\mathrm{c}}$ & $3.4 \pm 0.24^{\mathrm{c}}$ \\
Ethyl acetate fraction & 100 & $3.6 \pm 0.27^{\mathrm{bc}}$ & $4.4 \pm 0.24^{\mathrm{bc}}$ \\
Petroleum ether fraction & 100 & $5.6 \pm 0.24^{\mathrm{a}}$ & $6.6 \pm 0.24^{\mathrm{a}}$ \\
Aqueous fraction & 100 & $4.4 \pm 0.24^{\mathrm{b}}$ & $4.6 \pm 0.24^{\mathrm{b}}$ \\
Cyclophosphamide & 50 & $3.4 \pm 0.24^{\mathrm{bc}}$ & $3.6 \pm 0.24^{\mathrm{bc}}$ \\
\hline
\end{tabular}

Values along the same column with different superscripts are statistically significant to each other using Tukey's HSD test $(P<0.05)$.

measured with micrometre calliper (pitch $0.01 \mathrm{~mm}$ ) at 24 and $48 \mathrm{~h}$ of SRBC's challenge.

2.6. Statistical Analysis. Data were expressed as mean \pm S.E.M and statistical analysis was carried out employing the ANOVA followed by Tukey's HSD test using SPSS 16 software.

\section{Results}

3.1. Carrageenan-Induced Paw Edema. Different plant extracts used in the current study were found to show an anti-inflammatory activity. As compared to control group the treated groups showed decrease in the edema formation after $4 \mathrm{hrs}$. Ethyl acetate and aqueous fractions produced an inhibition of $23.81 \%$ and $28.57 \%$, respectively, in the paw edema. Petroleum ether fraction was found to have the minimum inhibition in edema $(7.62 \%)$. The maximum inhibition (47.62\%) in the edema formation was obtained in the methanolic fraction at a dose of $250 \mathrm{mg} / \mathrm{kg}$ bw (Table 1). Diclofenac was used as a standard anti-inflammatory drug at a dose of $20 \mathrm{mg} / \mathrm{kg}$ bw. The results obtained in the methanolic fraction were found to be significantly $(P<0.05)$ related to diclofenac treated group (55.24\%).

3.2. Haemagglutination Antibody Titre. The antibody titre was carried out to evaluate the influence of extracts on the production of antibodies by B-cells. The extracts were administered to the mice at a dose of $100 \mathrm{mg} / \mathrm{kg}$ bw and were seen to decrease the primary as well as the secondary immune response (Table 2). Methanolic extract showed marked

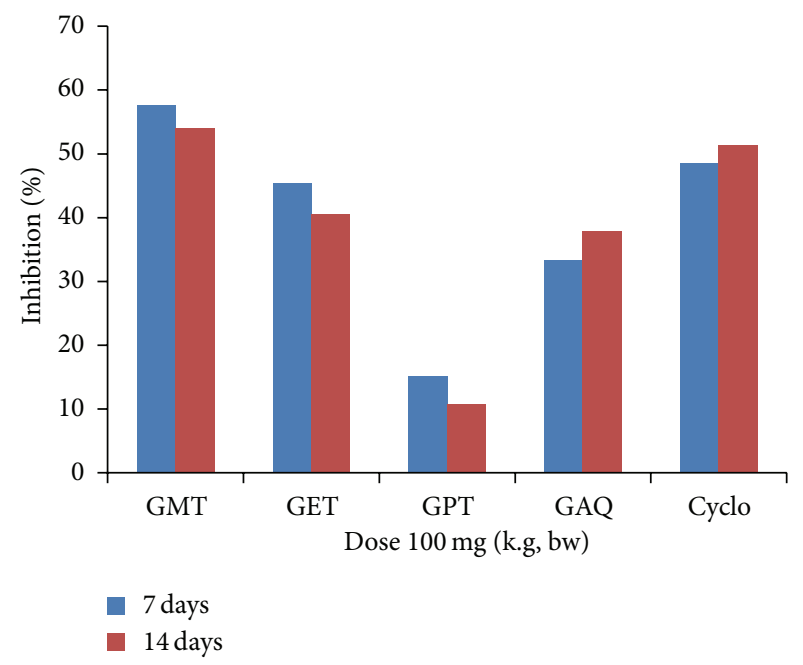

FIGURE 1: Graph showing \% age inhibition of primary and secondary response in Balb/C mice by different fractions of Gentiana kurroo Royle.

decrease in the HA titre as compared to control with the percentage of age inhibition of $57.57 \%$ and $54.05 \%$ in the primary and secondary response, respectively (Figure 1). The other extracts showed less effect on humoral response with the least effect observed in petroleum ether extract. The results obtained in the cyclophosphamide treated group were found to be insignificant $(P<0.05)$ in relation with the methanolic extract treated group and control group. 
TABLE 3: Effect of different extracts of Gentiana kurroo Royle on SRBC specific cellular immune response in Balb/C mice (mean \pm S.E) $(n=5)$.

\begin{tabular}{lccr}
\hline & \multicolumn{3}{c}{ DTH assay } \\
Groups & Dose $(\mathrm{mg} / \mathrm{kg})$ & $24 \mathrm{hr}$ paw thickness $(\mathrm{mm})$ & $48 \mathrm{hr}$ paw thickness $(\mathrm{mm})$ \\
\hline Control & SRBC & $0.72 \pm 0.016^{\mathrm{a}}$ & $0.4 \pm 0.027^{\mathrm{a}}$ \\
Methanolic fraction & 100 & $0.25 \pm 0.021^{\mathrm{d}}$ & $0.1 \pm 0.013^{\mathrm{d}}$ \\
Ethyl acetate fraction & 100 & $0.41 \pm 0.019^{\mathrm{c}}$ & $0.22 \pm 0.032^{\mathrm{c}}$ \\
Petroleum ether fraction & 100 & $0.61 \pm 0.035^{\mathrm{b}}$ & $0.35 \pm 0.04^{\mathrm{ab}}$ \\
Aqueous fraction & 100 & $0.47 \pm 0.016^{\mathrm{c}}$ & $0.25 \pm 0.029^{\mathrm{bc}}$ \\
Cyclophosphamide & 50 & $0.27 \pm 0.009^{\mathrm{d}}$ & $0.08 \pm 0.007^{\mathrm{d}}$ \\
\hline
\end{tabular}

Values along the same column with different superscripts are statistically significant to each other using Tukey's HSD test $(P<0.05)$.

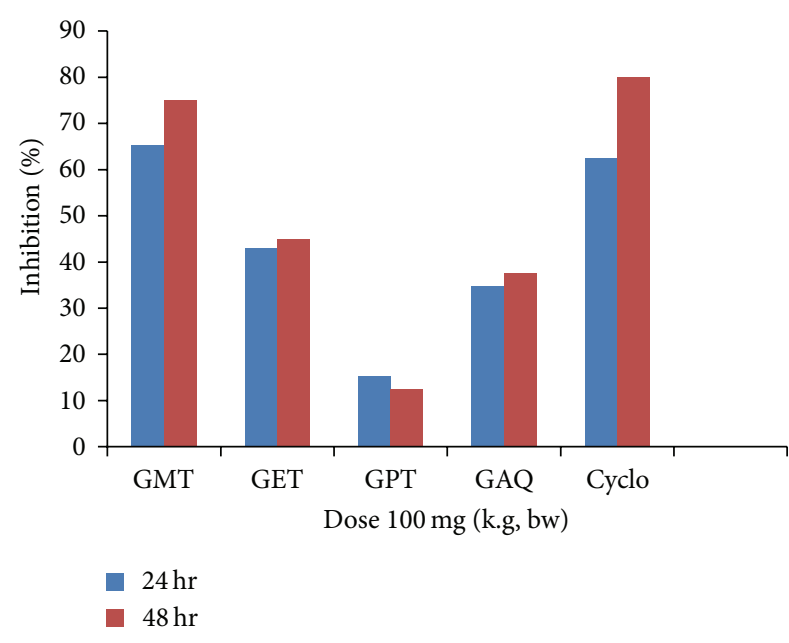

FIGURE 2: Graph showing $24 \mathrm{~h}$ and $48 \mathrm{~h} \%$ age inhibition of cell mediated response in mice by different fractions of Gentiana kurroo Royle.

3.3. Delayed-Type Hypersensitivity. DTH was carried out to study the effect of the different plant extracts on the nonspecific cellular immune response. All the plant extracts tested were found to decrease the cellular immune response (Table 3). The effect on edema formation was studied after $24 \mathrm{~h}$ and $48 \mathrm{~h}$ with the extracts fed to the mice at a dose of $100 \mathrm{mg} / \mathrm{kg}$ bw. The results obtained in the methanolic extract treated group significantly $(P<0.05)$ showed the inhibition of $65.27 \%$ and $75 \%$ of edema formation after $24 \mathrm{~h}$ and $48 \mathrm{~h}$, respectively (Figure 2). Petroleum extract treated group was observed to have minimum suppressive effect on cellular immune response with inhibition of $15.27 \%$ and $12.5 \%$ after $24 \mathrm{~h}$ and $48 \mathrm{~h}$. In the standard group treated with cyclophosphamide at a dose of $50 \mathrm{mg} / \mathrm{kg}$, the percentage of age inhibition obtained was $62.5 \%$ and $80 \%$ as compared to control group. The results obtained were found to be significant in relation with control group at $P<0.05$.

\section{Discussion}

Inflammation is a protective process that is essential for the preservation of the integrity of the organism in the event of physical, chemical, and infectious damage. Often, it is found that inflammatory response to severe lesions erroneously damages normal tissue [16]. Analysis of the results in the present study indicated that the different extracts of G. kurroo have anti-inflammatory potential. Of these different extracts methanolic fraction was found to have the maximum activity. This may be because of the presence of more bioactive agent(s) in this fraction. Most of the bioactive agents present in the medicinal herbs belong to secondary metabolites. These may be terpenoids or flavonoids in nature. As many monoterpenoids like camphene, borneol, and $\beta$-pinene are known to possess an anti-inflammatory property $[17,18]$, flavonoids like 6-methoxytricin have been seen to show anti-inflammatory and analgesic activities [19]. During acute inflammation leukocytes and serum proteins migrate to areas of tissue injury. Recruitment of cells to inflammatory sites is dependent on the release of vasoactive and chemotactic factors that increase regional blood flow and microvascular permeability and promote the migration of leukocytes from the intravascular space into the tissues [20]. It is well established that activated immunocytes are involved in the inflammation process, particularly macrophages, which play a crucial role in the specific and nonspecific immune responses during inflammation [21]. Further these fractions were used to demonstrate the effect on the immune system using Balb/C model for the study. All the fractions were again observed to have an immunosuppressive effect by inhibiting the antibody formation and the cellular immune response. Methanolic fraction was again found to have more inhibitory effect on the immune response. No such earlier study is found to be carried out on this plant. The results of the present study show that G. kurroo possesses an anti-inflammatory potential and this may be because of the decrease in both the specific and nonspecific immune response.

\section{Conclusion}

G. kurroo is a medicinal herb endemic to northwestern Himalayas. This plant is locally used for the treatment of many diseases. The current study was undertaken to explore the folklore claim of this plant. From the results demonstrated above, it seems that the plant may be an important reservoir of natural drugs. The results suggest that the plant can be a useful drug resource for the treatment of inflammatory diseases and several immunostimulant clinical conditions. Further 
studies are needed for the isolation and identification of the bioactive components in the plant.

\section{Conflict of Interests}

The authors declare that they have no conflict of interests.

\section{Acknowledgment}

The authors are highly thankful to the Indian Institute of Integrative Medicine (IIIM), Jammu, for providing the facilities for accomplishing this research work.

\section{References}

[1] K. Srinivasan, S. Muruganandan, J. Lal, S. Chandra, S. K. Tandan, and V. Ravi Prakash, "Evaluation of anti-inflammatory activity of Pongamia pinnata leaves in rats," Journal of Ethnopharmacology, vol. 78, no. 2-3, pp. 151-157, 2001.

[2] M. Bettini and D. A. Vignali, "Regulatory T cells and inhibitory cytokines in autoimmunity," Current Opinion in Immunology, vol. 21, no. 6, pp. 612-618, 2009.

[3] R. C. Dutta, "Peptide immunomodulators versus infection; an analysis," Immunology Letters, vol. 83, no. 3, pp. 153-161, 2002.

[4] M. Perretti and F. D’Acquisto, "Annexin Al and glucocorticoids as effectors of the resolution of inflammation," Nature Reviews Immunology, vol. 9, no. 1, pp. 62-70, 2009.

[5] K. De Bosscher, K. Van Craenenbroeck, O. C. Meijer, and G. Haegeman, "Selective transrepression versus transactivation mechanisms by glucocorticoid receptor modulators in stress and immune systems," European Journal of Pharmacology, vol. 583, no. 2-3, pp. 290-302, 2008.

[6] E. M. Souza-Fagundes, G. Gazzinelli, G. G. Parreira et al., "In vitro activity of labdane diterpene from Alomia myriadenia (Asteraceae): immunosuppression via induction of apoptosis in monocytes," International Immunopharmacology, vol. 3, no. 3, pp. 383-392, 2003.

[7] A. Mirshafiey, M. R. Khorramizadeh, F. Saadat, and B. H. A. Rehm, "Chemopreventive effect of M2000, a new anti-inflammatory agent," Medical Science Monitor, vol. 10, no. 10, pp. PI105-PI109, 2004.

[8] K. R. Kirtikar and B. D. Basu, Indian Medicinal Plants, Bishen Singh Mahendra Pal Singh, Dehradun, India, 1935.

[9] B. A. Wani, D. Ramamoorthy, and B. A. Ganai, "Preliminary phytochemical screening and evaluation of analgesic activity of methanolic extract of roots of Gentiana Kurroo Royle in experimental animal models," International Journal of Pharmacy and Pharmaceutical Sciences, vol. 3, no. 4, pp. 164-166, 2011.

[10] A. Latif, T. F. Khan, and S. H. Afaq, "Anti-inflammatory activity of flower tops of Gentiana kurroo Royale extract," Pharmacologyonloine, vol. 3, pp. 575-580, 2006.

[11] C. A. Winter, E. A. Risley, and G. W. Nuss, "Carrageenininduced edema in hind paw of the rat as an assay for antiiflammatory drugs," Proceedings of the Society for Experimental Biology and Medicine, vol. 111, pp. 544-547, 1962.

[12] D. P. Bhagwat, M. D. Kharya, S. Bani et al., "Immunosuppressive properties of Pluchea lanceolata leaves," Indian Journal of Pharmacology, vol. 42, no. 1, pp. 21-26, 2010.
[13] M. Thakur, P. Connellan, M. A. Deseo, C. Morris, and V. K. Dixit, "Immunomodulatory polysaccharide from Chlorophytum borivilianum roots," Evidence-Based Complementary and Alternative Medicine, vol. 2011, Article ID 598521, 7 pages, 2011.

[14] K. Mangathayaru, M. Umadevi, and C. U. Reddy, "Evaluation of the immunomodulatory and DNA protective activities of the shoots of Cynodon dactylon," Journal of Ethnopharmacology, vol. 123, no. 1, pp. 181-184, 2009.

[15] M. G. Jayathirtha and S. H. Mishra, "Preliminary immunomodulatory activities of methanol extracts of Eclipta alba and Centella asiatica," Phytomedicine, vol. 11, no. 4, pp. 361-365, 2004.

[16] A. Lunardelli, C. E. Leite, M. Guerra Simões Pires, and J. Rodrigues De Oliveira, "Extract of the bristles of Dirphia sp. increases nitric oxide in a rat pleurisy model," Inflammation Research, vol. 55, no. 4, pp. 129-135, 2006.

[17] C.-T. Lin, C.-J. Chen, T.-Y. Lin, J. C. Tung, and S.-Y. Wang, "Antiinflammation activity of fruit essential oil from Cinnamomum insularimontanum Hayata," Bioresource Technology, vol. 99, no. 18, pp. 8783-8787, 2008.

[18] Y.-T. Tung, M.-T. Chua, S.-Y. Wang, and S.-T. Chang, "Antiinflammation activities of essential oil and its constituents from indigenous cinnamon (Cinnamomum osmophloeum) twigs," Bioresource Technology, vol. 99, no. 9, pp. 3908-3913, 2008.

[19] Y. Yin, F.-Y. Gong, X.-X. Wu et al., "Anti-inflammatory and immunosuppressive effect of flavones isolated from Artemisia vestita," Journal of Ethnopharmacology, vol. 120, no. 1, pp. 1-6, 2008.

[20] A. F. Suffredini, G. Fantuzzi, R. Badolato, J. J. Oppenheim, and N. P. O'Grady, "New insights into the biology of the acute phase response," Journal of Clinical Immunology, vol. 19, no. 4, pp. 203214, 1999.

[21] G. R. . Romeo, J. Lee, and S. E. Shoelson, "Metabolic syndrome, insulin resistance and roles of inflammation: mechanisms and therapeutic targets," Arteriosclerosis, Thrombosis, and Vascular Biology, vol. 32, pp. 1771-1776, 2012. 


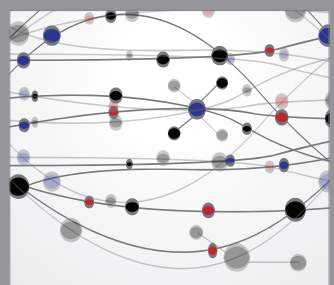

The Scientific World Journal
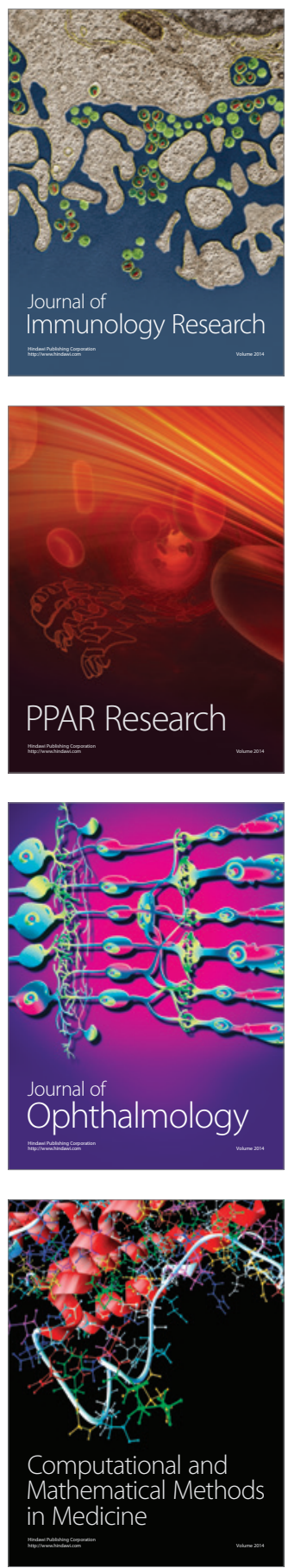

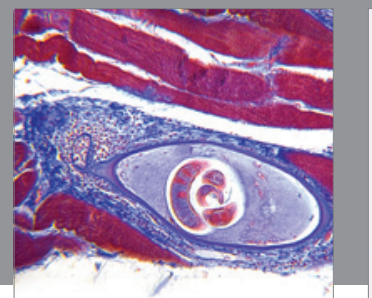

Gastroenterology

Research and Practice
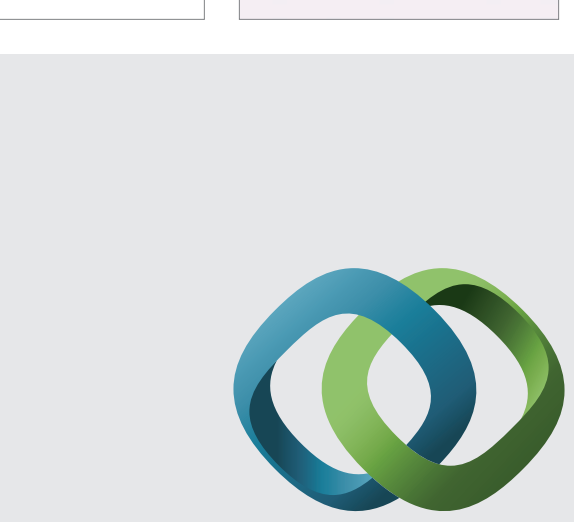

\section{Hindawi}

Submit your manuscripts at

http://www.hindawi.com
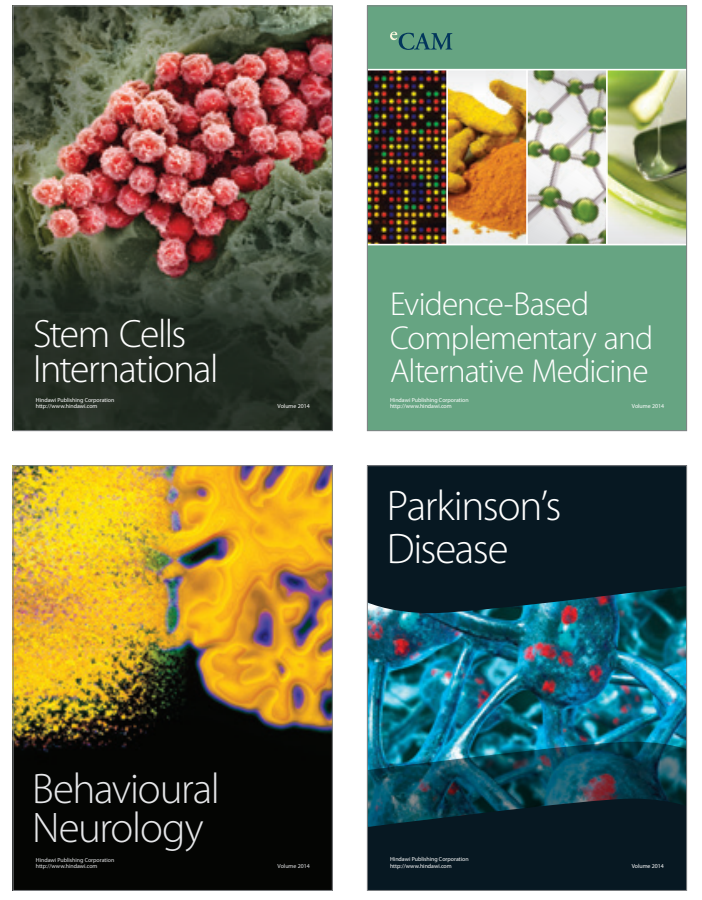
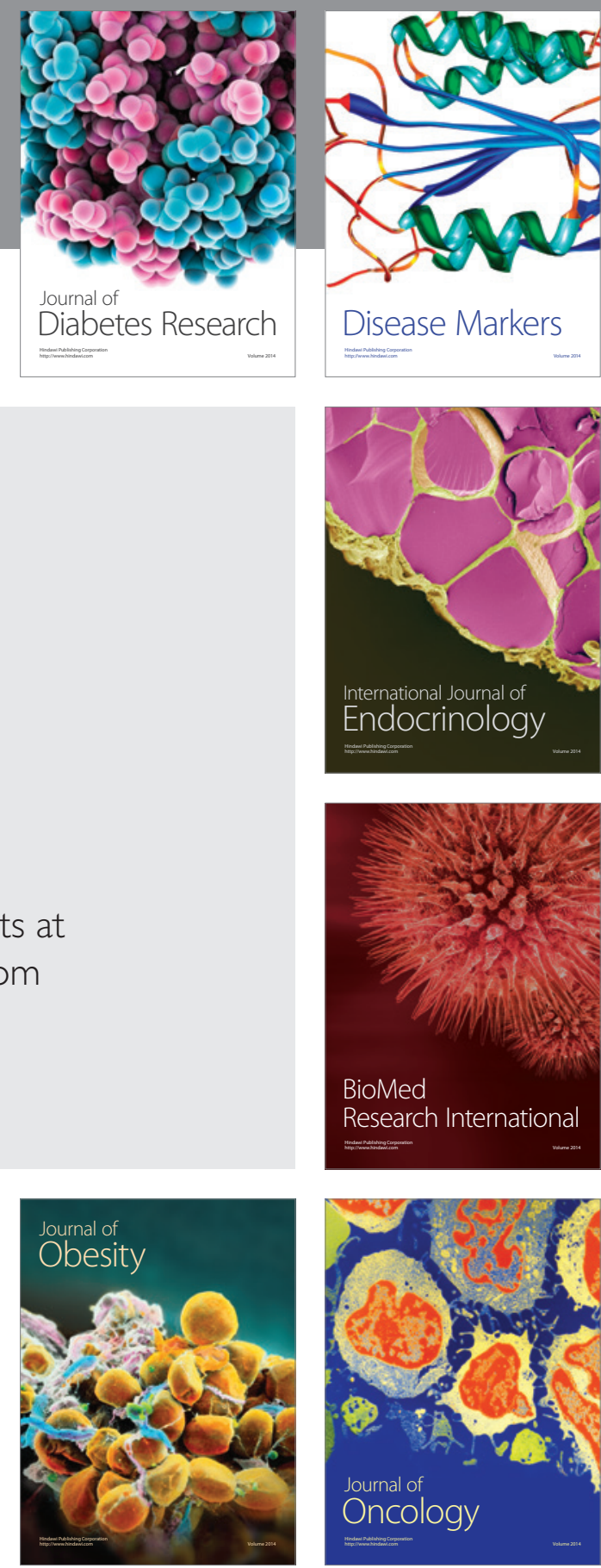

Disease Markers
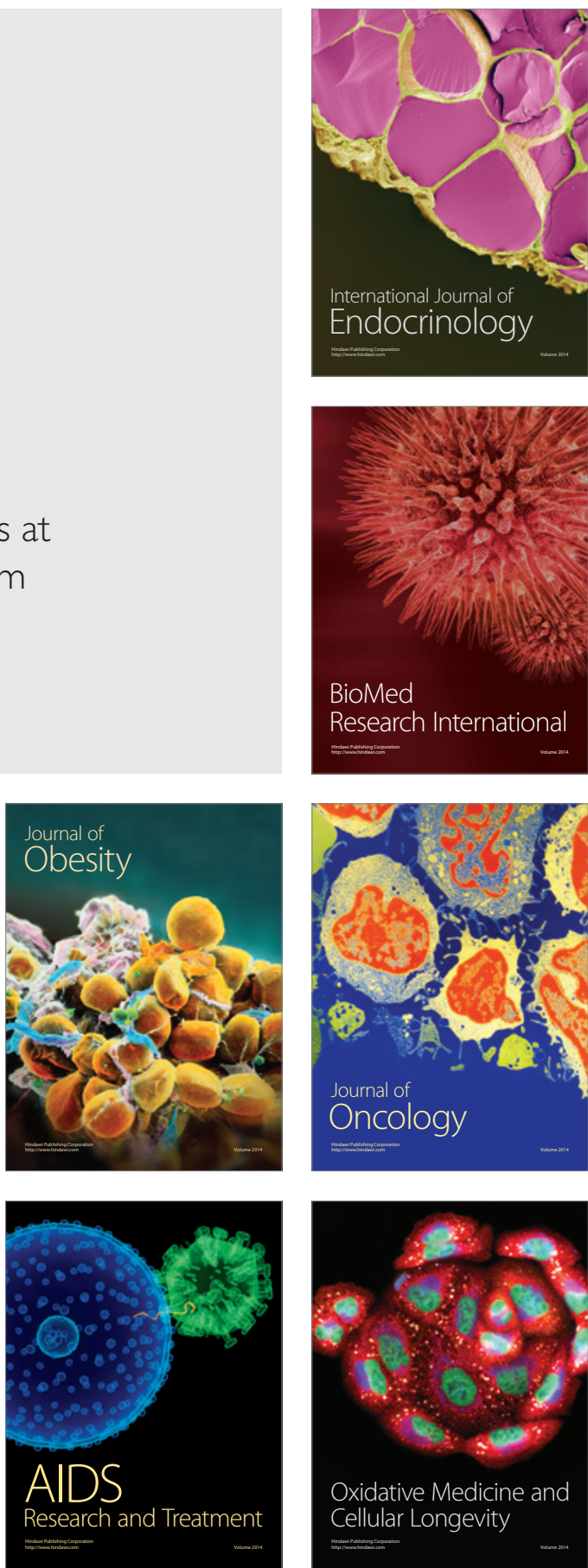